\title{
Contact lenses at high altitude: experience on Everest south-west face 1975
}

\author{
CHARLES CLARKE \\ The Middlesex Hospital, London
}

Although contact lenses have been worn for several decades by Alpine climbers, skiers, and civilian aircraft personnel there is no record of their use on expeditions to altitudes higher than $15000 \mathrm{ft}$ $(4560 \mathrm{~m})$, and in particular to Himalayan peaks where supplementary oxygen is required. Thus a record of the experience of those members of the British Everest Expedition who wore or tried to wear contact lenses at high altitude during the autumn of 1975 is of interest.

\section{Subjects and results}

Five members were fitted with Permalenses during the spring and early summer and, after some initial problems with fitting, all became accustomed to wearing them continuously in Britain. One man climbed to $20000 \mathrm{ft}$ $(6080 \mathrm{~m})$ in the Karakoram before the Everest expedition and was able to use the lenses, and a second, a mountaineering camera man, had no difficulties with them during work in Europe.

The r 975 Everest expedition may conveniently be divided into three stages. (I) The march across Nepal to base camp at $18000 \mathrm{ft}(5472 \mathrm{~m})$ in the monsoon weather of August. (2) The climb from base to camp 4 on the south-west face at $24000 \mathrm{ft}(7296 \mathrm{~m})$. This was done without supplementary oxygen. (3) Work above $24000 \mathrm{ft}$, when oxygen was usually used while ascending and at a reduced rate while sleeping.

During the three-week approach to base camp there was little reason to expect problems. The group were travelling in warm, moist weather with temperatures up to $35^{\circ} \mathrm{C}$. This period served as a useful time to assess the motivation of the five climbers to continue to use the lenses on the mountain. Three had had great problems on previous trips with glasses misting up, and were thus keen to use them higher. One, on his own admission, was careless and found that he was unable to refrain from rubbing his eyes in the mornings: he lost the original pair of lenses and soon lost another pair. The other climber had had little trouble with glasses and found he simply preferred them.

The second part of the expedition up to $24000 \mathrm{ft}$ was wholly on snow and ice, and by day everyone wore either goggles, a screen, or sunglasses with side pieces. Quite apart from the need to avoid snow blindness, the eyes were thus shielded from wind and spindrift. One of the three remaining lens users thought that his visual acuity was poorer than with glasses and, although vision on testing was $6 / 6$ bilaterally, he preferred to remove the contact lenses. The other two lens users changed to spare lenses on two occasions during this three-week period after the lenses had slipped from the cornea during the night. Otherwise they found the lenses very acceptable. These two climbers worked on the mountain above $24000 \mathrm{ft}$. The Blume-Robertshaw demand oxygen system was used by day with a close fitting mask which covered only the mouth and nose, while at night a looser polythene mask was used on a constant flow system. Both climbers finally stopped using the lenses at about $26000 \mathrm{ft}(7904 \mathrm{~m})$, each after several days. On one occasion a lens slipped in the night and there was moderate conjunctivitis. Of the remaining climber, our camera man, it is known that his lenses were uncomfortable and that he had reverted to glasses by the time of his death near the summit of Everest. These results are summarized in the Table.

Table Duration of continuous wear of hydrogel contact lenses at high altitude

\begin{tabular}{|c|c|c|}
\hline Subject & $\begin{array}{l}\text { Periods of continuous wear } \\
\text { (days) }\end{array}$ & Comments \\
\hline $\mathbf{A}$ & $4(5000$ to $8000 \mathrm{ft})$ & $\begin{array}{l}\text { Initial pair lost after } \\
\text { two days. Poorly } \\
\text { motivated }\end{array}$ \\
\hline $\begin{array}{l}\text { B } \\
\text { C } \\
\text { D }\end{array}$ & $\begin{array}{l}3(5000 \text { to } 8000 \mathrm{ft}) \\
12(5000 \text { to } 19000 \mathrm{ft}) \\
\text { (a) } 40(\text { sea level to } 18000 \mathrm{ft})^{*} \\
\text { (b) } 14(5000 \text { to } 18000 \mathrm{ft})^{*} \\
\text { (c) } 10(20000 \text { to } 26000 \mathrm{ft})^{*}\end{array}$ & $\begin{array}{l}\text { Preferred glasses } \\
\text { Preferred glasses } \\
\text { Lost lens in a bivouac } \\
\text { Lens slipped at night } \\
\text { Lenses uncomfortable } \\
\text { Two changes of lenses } \\
\text { during (c) }\end{array}$ \\
\hline $\mathbf{E}$ & Over $50(5000$ to $26000 \mathrm{ft})$ & $\begin{array}{l}\text { Two changes when a } \\
\text { lens slipped during } \\
\text { night but no rest } \\
\text { periods without lenses }\end{array}$ \\
\hline
\end{tabular}

*Rest periods of about 2 weeks each divided these continuous periods

I000 feet $=304$ metres

\section{Discussion}

Although contact lens practitioners have commented on the difficulties which wearers have in cities as low as Denver, Colorado (Harper, 1973), it is striking that two men on this expedition were able to use hydrogel lenses up to $24000 \mathrm{ft}$. The eyes of all members of the team were examined often (as part of a study of high altitude retinal 
haemorrhages and to measure the intraocular pressure) and it was not clinically noticeable that the two long-standing contact lens wearers had more conjunctival injection than their colleagues. In both cases a limited examination of the cornea was normal. Illumination was provided by a slit light of a 12-volt Keeler Pantoscope and the ${ }_{13} D$ achromatic condensing lens was used as an objective. The cornea was then stained with fluorescein.

The ambient oxygen tension at $20000 \mathrm{ft}$ is of the order of $65 \mathrm{mmHg}$ and at $24000 \mathrm{ft} 55 \mathrm{mmHg}$. At the summit of Everest it falls to about $45 \mathrm{mmHg}$. The minimum surface oxygen tension for normal corneal function is said to be of the order of $\mathrm{I}_{5}$ mmHg (Fatt, I97 I and 1972; Polse and Mandell, 1970) and it is interesting to speculate how nearly this critical level is reached at high altitude, particularly during sleep. We were surprised to find the lenses well tolerated by two climbers below $24000 \mathrm{ft}$ and doubtless they will be used again by high altitude mountaineers.

\section{Summary}

Five members of the British Everest Expedition I975 were equipped with hydrogel contact lenses. Some clinical observations are made about the performance of these lenses. Two men were able to use them up to an altitude of $24000 \mathrm{ft}$, where the ambient oxygen tension is of the order of $55 \mathrm{mmHg}$.

I thank Mr John Evans, of Global Vision (UK) Ltd, and $\mathrm{Mr}$ John de Carle for their help in supplying and fitting the lenses, and Professor Irving Fatt, of the University of California, Berkeley, Wing Commander Brennan, and Squadron Leader Denison of the Royal Aircraft Establishment for guidance. The ocular studies on Everest were financed by a grant from the Department of Neurological Studies, the Middlesex Hospital.

\section{References}

FATT, I. (1971) Amer. F. Optom., 48, 545 (1972) Contact Lens, 4, 3

harPer, s. A. (1973) Contact Lens Soc. Amer. F., 7, 23

POLSE, K. A., and MANDELl, R. B. (r970) Arch. Ophthal., 84, 505 